\title{
A generalized forward-backward method for solving split equality quasi inclusion problems in Banach spaces
}

\author{
Shih-Sen Chang ${ }^{\mathrm{a}, \mathrm{b}}$, Ching-Feng Wen ${ }^{\mathrm{c}, \mathrm{d}, *}$, Jen-Chih $\mathrm{Yao}^{\mathrm{a}}$, Jing-Qiang Zhang ${ }^{\mathrm{b}}$ \\ ${ }^{a}$ Center for General Education, China Medical University, Taichung, 40402, Taiwan. \\ ${ }^{b}$ College of Statistics and Mathematics, Yunnan University of Finance and Economics, Kunming, Yunnan 650221, China. \\ ${ }^{c}$ Center for Fundamental Science; and Research Center for Nonlinear Analysis and Optimization, Kaohsiung Medical University, \\ Kaohsiung 80702, Taiwan. \\ ${ }^{d}$ Department of Medical Research, Kaohsiung Medical University Hospital, Kaohsiung 80702, Taiwan.
}

Communicated by P. Kumam

\begin{abstract}
A generalized forward-backward method for solving split equality quasi inclusion problems of accretive operators in Banach spaces is studied. Some strong convergence theorems for the sequences generalized by the algorithm to a solution of quasi inclusion problems of accretive operators are proved under certain assumptions. The results presented in this paper are new which extend and improve the corresponding results announced in the recent literatures. At the end of the paper some applications to monotone variational inequalities, convex minimization problem, and convexly constrained linear inverse problem are presented. (C)2017 All rights reserved.
\end{abstract}

Keywords: Generalized forward-backward method, accretive operator, m-accretive operator, maximal monotone operator, split equality quasi inclusion problem.

2010 MSC: $47 \mathrm{H} 09,47 \mathrm{H} 10,47 \mathrm{~N} 10$.

\section{Introduction}

The quasi inclusion problem for monotone and the maximal monotone mappings in the setting of Hilbert space has been considered by many authors (see, for example $[3,4,6,7,10,11,17])$. This problem includes, as special cases, convex programming, variational inequalities, split feasibility problem, and minimization problem. To be more precise, some concrete problems in machine learning, image processing and linear inverse problem can be modeled mathematically as this form $[1,7,8]$. A classical method for solving this problem is the forward-backward splitting method [3, 7, 10, 21]. In fact, this method includes, in particular, the proximal point algorithm $[3,8,12,17]$ and the gradient method [10].

Attempt to introduce and consider the quasi inclusion problem, common null point problem and

\footnotetext{
*Corresponding author

Email addresses: changss2013@163.com (Shih-Sen Chang), cf wen@kmu.edu.tw (Ching-Feng Wen), yaojc@mail.cmu.edu.tw (Jen-Chih Yao), geminitiger@163.com (Jing-Qiang Zhang)

doi:10.22436/jnsa.010.09.29
} 
others relative problems in the setting of Banach spaces have recently been made. In 2012, López et al. [11], and Cholamjiak [4] introduced and studied the quasi inclusion problem for accretive and the maccretive mappings in Banach spaces. By using the Halpern-type forward-backward method and under some appropriate conditions they proved that the sequence generated by the algorithm converges strongly to a solution of the quasi inclusion problem. In 2015, Takahashi [19] introduced and studied the common null point problem in Banach spaces. Also in 2016, Chang et al. [2] introduced and studied the split equality variational inclusion problems in the setting of Banach spaces.

Motivated by the above works and related literatures, the purpose of this paper is to introduce and study the so-called split equality quasi inclusion problems for accretive and the m-accretive mappings in Banach spaces. For solving this split quasi inclusion problem, we introduce and study a generalized forwardbackward method in the framework of Banach spaces. The strong convergence theorems of the sequences generalized by the algorithm to a solution of the quasi inclusion problem are proved under certain assumptions. The results presented in this paper seem to be the first outside Hilbert space which extend and improve the main results of Chen and Rockafellar [3], Cholamjiak [4], Lions and Mercier [10], López et al. [11], Moudafi [15] and Takahashi et al. [20]. At the end of the paper, some applications to monotone variational inequalities, convex minimization problem and convexly constrained linear inverse problem are presented also.

\section{Preliminaries}

In this section we shall recall some notions and results which will be needed in proving our main results.

Let $E_{1}, E_{2}$ and $F$ be three real Banach spaces, $G_{i}: E_{i} \rightarrow E_{i}, i=1,2$ be nonlinear mappings, $K_{i}: E_{i} \rightrightarrows$ $E_{i}, i=1,2$ be set-valued mappings, and $A: E_{1} \rightarrow F$ and $B: E_{2} \rightarrow F$ be two linear bounded operators. The so-called split equality quasi inclusion problem in Banach spaces is to find $x^{*} \in E_{1}, y^{*} \in E_{2}$ such that

$$
\left\{\begin{array}{l}
0 \in \mathrm{G}_{1} \mathrm{x}^{*}+\mathrm{K}_{1} \mathrm{x}^{*}, \\
0 \in \mathrm{G}_{2} \mathrm{y}^{*}+\mathrm{K}_{2} \mathrm{y}^{*},
\end{array} \quad \mathrm{~A} \mathrm{x}^{*}=\mathrm{B} \mathrm{y}^{*} .\right.
$$

\section{Special cases:}

(I) In (2.1), if $F=E_{2}$ and $B=I$ (identity mapping on $F$ ), then the problem (2.1) is equivalent to the following problem: find $x^{*} \in \mathrm{E}_{1}$ such that

$$
\left\{\begin{array}{l}
0 \in \mathrm{G}_{1} x^{*}+\mathrm{K}_{1} x^{*}, \\
0 \in \mathrm{G}_{2}\left(A x^{*}\right)+\mathrm{K}_{2}\left(A x^{*}\right),
\end{array}\right.
$$

which is called split quasi inclusion problem. This kind of problems has been considered by Chang et al. [2] recently. And it was also considered by Moudafi [13-15] in Hilbert spaces. This problem can be used in various disciplines such as game theory, image restoration, computer tomograph radiation therapy treatment planning, and decomposition methods for PDEs.

(II) In (2.1), if $F=E_{1}=E_{2}, G_{1}=G_{2}, K_{1}=K_{2}$ and $A=B=I$ (identity mapping on $F$ ), then the problem (2.1) is equivalent to the following quasi inclusion problem: find $x^{*} \in F$ such that

$$
0 \in \mathrm{G} x^{*}+\mathrm{K} x^{*} \text {. }
$$

This problem has been considered by many authors (see, for example $[3,4,6,7,10,11,17])$. Some concrete problems in machine learning such as convex programming, variational inequalities, minimization problem, image processing, and linear inverse problem can be modeled mathematically as this form $[1,7,8]$. The following provides some examples of problem (2.3).

Example 2.1. A stationary solution to the initial value problem of the evolution equation

$$
0 \in \frac{\partial u}{\partial t}+F u, u(0)=u_{0}
$$

can be rewritten as (2.3) when the governing maximal monotone $F$ is of the form $F=G+K$. 
Example 2.2. In optimization, it often needs to solve a minimization problem of the form

$$
\min _{x \in H}\{f(x)+g(T x)\}
$$

where $\mathrm{H}$ is a real Hilbert space, and $f, g$ are proper lower semicontinuous and convex functions from $H$ to $]-\infty, \infty]$ and $\mathrm{T}$ is a bounded linear operator on $\mathrm{H}$.

Indeed, (2.4) is equivalent to (2.3) if $f$ and $g \circ T$ have a common point of continuity with $G:=\partial f$ and $\mathrm{K}:=\mathrm{T}^{*} \circ \partial \mathrm{g} \circ \mathrm{T}$. Here $\mathrm{T}^{*}$ is the adjoint of $\mathrm{T}$ and $\partial \mathrm{f}$ is the subdifferential operator of $\mathrm{f}$. It is known $[1,7,12,17,18]$ that the minimization problem (2.4) is widely used in image recovery, signal processing, and machine learning.

Example 2.3. If $K=\partial \phi: H \rightrightarrows H$ is a set-valued mapping, where $\phi: H \rightarrow(-\infty, \infty]$ is a proper convex and lower semicontinuous function, and $\partial \phi$ is the subdifferential of $\phi$, then problem (2.3) is equivalent to find $x^{*} \in \mathrm{H}$ such that

$$
\left\langle G x^{*}, v-x^{*}\right\rangle+\phi(v)-\phi\left(x^{*}\right) \geqslant 0, \forall v \in H,
$$

which is said to be the mixed quasi-variational inequality.

Example 2.4. In Example 2.3, if $\phi$ is the indicator function of $C$, i.e.,

$$
\phi(x)= \begin{cases}0, & \text { if } x \in C, \\ +\infty, & \text { if } x \notin C,\end{cases}
$$

then problem (2.5) is equivalent to the classical variational inequality problem, denoted by VI(C; G), i.e., to find $x^{*} \in \mathrm{C}$ such that

$$
\left\langle\mathrm{G} x^{*}, v-x^{*}\right\rangle \geqslant 0, \forall v \in \mathrm{C} .
$$

It is easy to see that the problem (2.6) is equivalent to find a point $x^{*} \in \mathrm{C}$ such that

$$
0 \in(\mathrm{G}+\mathrm{K}) \mathrm{x}^{*},
$$

where $\mathrm{K}$ is the subdifferential of the indicator of $\mathrm{C}$.

In the sequel, we always denote by $\operatorname{Fix}(T)$ the set of fixed points of a mapping $T$ and denote by $x_{n} \rightarrow x^{*}$ and $x_{n} \rightarrow x^{*}$ the strong convergence and weak convergence of the sequence $\left\{x_{n}\right\}$ to $x^{*}$, respectively.

In what follows we always assume that $X$ is a uniformly convex and q-uniformly smooth Banach space for some $q \in] 1,2]$ (for definitions and properties, see, for example [5]) and $X^{*}$ is the dual space of $X$.

Recall that the generalized duality mapping $\mathrm{J}_{\mathrm{q}}: \mathrm{X} \rightrightarrows \mathrm{X}^{*}$ is defined by

$$
\mathrm{J}_{\mathrm{q}}(x)=\left\{j_{\mathrm{q}}(x) \in X^{*}:\left\langle j_{\mathrm{q}}(x), x\right\rangle=\|x\| \cdot\left\|j_{\mathrm{q}}(x)\right\|, \quad\left\|j_{\mathrm{q}}(x)\right\|=\|x\|^{\mathbf{q}-1}\right\} .
$$

Especially, if $q=2$, then the generalized duality mapping $J_{q}$ is called normalized duality mapping and denoted by $J_{X}$.

Lemma 2.5. If $\mathrm{X}$ is a $\mathrm{q}$-uniformly smooth Banach space, $\mathrm{q} \in] 1,2]$, then the following conclusions hold:

(1) for any $x, y \in X[3]$,

$$
\|x+y\|^{q} \leqslant\|x\|^{q}+q\left\langle y, j_{q}(x+y)\right\rangle, j_{q}(x+y) \in J_{q}(x+y) ;
$$

(2) there exists a constant $\mathrm{K}_{\mathrm{q}}>0$ such that [22]

$$
\|x+y\|^{q} \leqslant\|x\|^{q}+q\left\langle y, j_{q}(x)\right\rangle+k_{q}\|y\|^{q}, x, y \in X .
$$

The best constant $\mathrm{K}_{\mathrm{q}}$ satisfying (2.8) will be called the q-uniform smoothness coefficient of $X$. 
Lemma 2.6 ([22]). Let $X$ be a uniformly convex Banach space. For any given number $r>0$, there exists a continuous strictly increasing function $\mathrm{g}:[0, \infty[\rightarrow[0, \infty[, \mathrm{g}(0)=0$ such that

$$
\|t x+(1-t) y\|^{2} \leqslant t\|x\|^{2}+(1-t)\|y\|^{2}-t(1-t) g(\|x-y\|)
$$

for all $x, y \in X$ with $\|x\| \leqslant r,\|y\| \leqslant r$, and $t \in[0,1]$.

Proposition 2.7 ([5]). Let $1<\mathrm{q} \leqslant 2$. Then the following conclusions hold:

(1) a Banach space $\mathrm{X}$ is smooth if and only if the duality mapping $\mathrm{J}_{\mathrm{q}}$ is single-valued;

(2) a Banach space $\mathrm{X}$ is uniformly smooth if and only if the duality mapping $\mathrm{J}_{\mathrm{q}}$ is single-valued and norm-to-norm uniformly continuous on bounded sets of $X$.

Recall that a set-valued operator $\mathrm{K}: \mathrm{X} \rightrightarrows \mathrm{X}$ with the domain $\mathrm{D}(\mathrm{K})$ and the range $\mathrm{R}(\mathrm{K})$ is said to be accretive if, for each $x, y \in D(K)$, there exists $j(x-y) \in J(x-y)$ such that

$$
\langle u-v, j(x-y)\rangle \geqslant 0, \forall u \in K x \text { and } v \in K y .
$$

An accretive operator $K$ is said to be $m$-accretive if the range $R(I+\lambda K)=X$, for all $\lambda>0$.

For $\alpha>0$ and $q \in] 1,2]$, we say that an accretive operator $G$ is $\alpha$-inverse strongly accretive (shortly, $\alpha$-isa) of order $q$, if for each $x, y \in D(G)$, there exists $j_{q}(x-y) \in J_{q}(x-y)$ such that

$$
\left\langle\mathrm{u}-v, \mathrm{j}_{\mathrm{q}}(\mathrm{x}-\mathrm{y})\right\rangle \geqslant \alpha\|\mathrm{u}-v\|^{\mathrm{q}}, \forall \mathrm{u} \in \mathrm{Gx} \text { and } v \in \mathrm{Gy} .
$$

It is easy to prove that the following conclusion holds.

Lemma 2.8. For any $r>0$, if

$$
S_{r}:=J_{r}^{K}(I-r G)=(I+r K)^{-1}(I-r G),
$$

then $\operatorname{Fix}\left(S_{r}\right)=(G+K)^{-1}(0)$.

Lemma 2.9 ([11, Lemma 3.3]). Let $\mathrm{X}$ be a uniformly convex and $\mathrm{q}$-uniformly smooth Banach space with $\mathrm{q} \in] 1,2]$. Assume that $\mathrm{G}$ is a single-valued $\alpha$-isa of order $\mathrm{q}$ on $\mathrm{X}$. Then, for any $\mathrm{r}>0$, there exists a continuous, strictly increasing, and convex function $\phi_{\mathrm{q}}: \mathrm{R}^{+} \rightarrow \mathrm{R}^{+}$with $\phi_{\mathrm{q}}(0)=0$ such that for all $\mathrm{x}, \mathrm{y} \in \mathrm{B}_{\mathrm{r}}$,

$$
\begin{aligned}
\left\|S_{r} x-S_{r} y\right\|^{q} \leqslant & \|x-y\|^{q}-r\left(\alpha q-r^{q-1} \kappa_{q}\right)\|G x-G y\|^{q} \\
& -\phi_{q}\left(\left\|\left(I-J_{r}^{K}\right)(I-r G) x-\left(I-J_{r}^{K}\right)(I-r G) y\right\|\right),
\end{aligned}
$$

where $\mathrm{K}_{\mathrm{q}}$ is the $\mathrm{q}$-uniform smoothness coefficient of $\mathrm{X}$.

Remark 2.10. It follows from (2.9) that if $0<\mathrm{r} \leqslant\left(\frac{\alpha q}{\mathrm{~K}_{\mathrm{q}}}\right)^{\frac{1}{q-1}}$, then $S_{\mathrm{r}}$ is a nonexpansive mapping.

\section{Main results}

We are now in a position to give the following main results.

Theorem 3.1. Let $\mathrm{E}_{1}, \mathrm{E}_{2}$ be real uniformly convex and 2-uniformly smooth Banach spaces with the best smoothness constant $k \in] 0,1$ and $F$ be a real Banach space. Let $G_{i}: E_{i} \rightarrow E_{i}, i=1,2$ be $\alpha$-isa of order 2 and $K_{i}: E_{i} \rightrightarrows$ $\mathrm{E}_{i}, i=1,2$ be set-valued m-accretive mappings, and $\mathrm{A}: \mathrm{E}_{1} \rightarrow \mathrm{F}$ and $\mathrm{B}: \mathrm{E}_{2} \rightarrow \mathrm{F}$ be two linear bounded operators. For any $\left(\mathrm{x}_{0}, \mathrm{y}_{0}\right) \in \mathrm{E}_{1} \times \mathrm{E}_{2}$, the sequence $\left\{\left(\mathrm{x}_{\mathrm{n}}, \mathrm{y}_{\mathrm{n}}\right)\right\}$ is generated by

$$
\left\{\begin{array}{l}
u_{n}=J_{r}^{K_{1}}\left(I-r G_{1}\right)\left(x_{n}-\gamma J_{E_{1}}^{-1} A^{*} J_{F}\left(A x_{n}-B y_{n}\right)\right), \\
v_{n}=J_{r}^{K_{2}}\left(I-r G_{2}\right)\left(y_{n}+\gamma J_{E_{2}}^{-1} B^{*} J_{F}\left(A x_{n}-B y_{n}\right)\right), \\
x_{n+1}=\left(1-\beta_{n}\right) u_{n}+\beta_{n}\left(x_{n}-\gamma J_{E_{1}}^{-1} A^{*} J_{F}\left(A x_{n}-B y_{n}\right)\right), \\
y_{n+1}=\left(1-\beta_{n}\right) v_{n}+\beta_{n}\left(y_{n}+\gamma J_{E_{2}}^{-1} B^{*} J_{F}\left(A x_{n}-B y_{n}\right)\right),
\end{array} \quad \forall n \geqslant 1 .\right.
$$


where $\mathrm{J}_{r}^{\mathrm{K}_{i}}:=\left(\mathrm{I}+\mathrm{rK}_{\mathrm{i}}\right)^{-1}, i=1,2$ is the resolvent operator of mapping $\mathrm{K}_{i}, \mathrm{~J}_{\mathrm{E}_{i}}, i=1,2$ and $\mathrm{J}_{\mathrm{F}}$ are the normalized duality mapping of $\mathrm{E}_{i}, i=1,2$ and $\mathrm{F}$, respectively, and $\mathrm{A}^{*}$ and $\mathrm{B}^{*}$ are the adjoints of $\mathrm{A}$ and $\mathrm{B}$, respectively. If

$$
\Gamma:=\left\{(x, y) \in \operatorname{Fix}\left(J_{r}^{K_{1}}\left(I-r G_{1}\right)\right) \times \operatorname{Fix}\left(J_{r}^{K_{2}}\left(I-r_{2}\right)\right), A x=B y\right\} \neq \emptyset
$$

and the following conditions are satisfied:

(i) $0<\gamma<\frac{1}{\mathrm{~L}}$, where $\mathrm{L}=\max \left\{\left\|\mathrm{A}^{*} \mathrm{~A}\right\|,\left\|\mathrm{B}^{*} \mathrm{~B}\right\|\right\}$;

(ii) $0<r \leqslant \frac{2 \alpha}{k}$;

(iii) $\left\{\beta_{n}\right\}$ is the sequence in $] 0,1\left[\right.$ with $\lim \inf \beta_{n}\left(1-\beta_{n}\right)>0$,

then the sequence $\left\{\left(x_{n}, y_{n}\right)\right\}$ converges strongly to a solution ( $\left.x^{*}, y^{*}\right)$ of split equality quasi inclusion problem (2.1).

Proof. For the sake of convenience, put

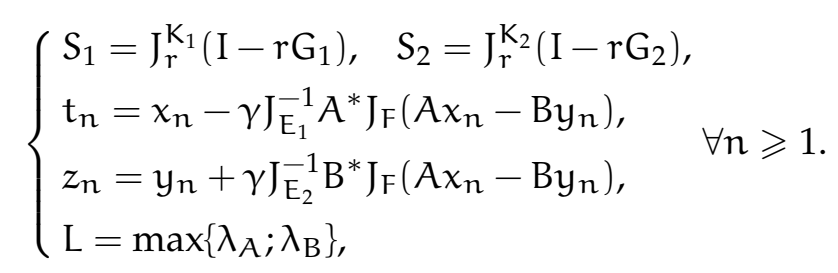

Then $\Gamma:=\left\{(x, y) \in \operatorname{Fix}\left(S_{1}\right) \times \operatorname{Fix}\left(S_{2}\right), A x=B y\right\} \neq \emptyset$, and (3.1) can be written as

$$
\left\{\begin{array}{l}
u_{n}=J_{r}^{K_{1}}\left(I-r G_{1}\right) t_{n}=S_{1} t_{n}, \\
v_{n}=J_{r}^{K_{2}}\left(I-r G_{2}\right) z_{n}=S_{2} z_{n}, \\
x_{n+1}=\left(1-\beta_{n}\right) u_{n}+\beta_{n} t_{n}=\left(1-\beta_{n}\right) S_{1} t_{n}+\beta_{n} t_{n}, \\
y_{n+1}=\left(1-\beta_{n}\right) v_{n}+\beta_{n} z_{n}=\left(1-\beta_{n}\right) S_{2} z_{n}+\beta_{n} z_{n},
\end{array} \forall n \geqslant 1 .\right.
$$

Observe that by condition (ii) and Lemma 2.9, $S_{i}: E_{i} \rightarrow E_{i}, i=1,2$ are nonexpansive mappings.

1. First we prove that the sequences $\left\{x_{n}\right\},\left\{y_{n}\right\},\left\{u_{n}\right\},\left\{v_{n}\right\},\left\{t_{n}\right\},\left\{z_{n}\right\}$ all are bounded.

Taking $(x, y) \in \Gamma$, then $x \in \operatorname{Fix}\left(S_{1}\right), y \in \operatorname{Fix}\left(S_{2}\right)$ and $A x=B y$. Hence we have

$$
\begin{aligned}
\left\|x_{n+1}-x\right\| & =\left\|\left(1-\beta_{n}\right)\left(u_{n}-x\right)+\beta_{n}\left(t_{n}-x\right)\right\| \\
& \leqslant\left(1-\beta_{n}\right)\left\|u_{n}-x\right\|+\beta_{n}\left\|t_{n}-x\right\| \\
& =\left(1-\beta_{n}\right)\left\|S_{1} t_{n}-S_{1} x\right\|+\beta_{n}\left\|t_{n}-x\right\| \\
& \leqslant\left(1-\beta_{n}\right)\left\|t_{n}-x\right\|+\beta_{n}\left\|t_{n}-x\right\| \\
& =\left\|t_{n}-x\right\| .
\end{aligned}
$$

Also it follows from Lemma 2.5 (2) that

$$
\begin{aligned}
\left\|t_{n}-x\right\|^{2} & =\left\|\gamma J_{E_{1}}^{-1} A^{*} J_{F}\left(A x_{n}-B y_{n}\right)+\left(x-x_{n}\right)\right\|^{2} \\
& \leqslant\left\|\gamma J_{E_{1}}^{-1} A^{*} J_{F}\left(A x_{n}-B y_{n}\right)\right\|^{2}+2 \gamma\left\langle x-x_{n}, J_{E_{1}} J_{E_{1}}^{-1} A^{*} J_{F}\left(A x_{n}-B y_{n}\right)\right\rangle+k\left\|x-x_{n}\right\|^{2} \\
& \leqslant \gamma^{2} L\left\|A x_{n}-B y_{n}\right\|^{2}+2 \gamma\left\langle A x-A x_{n}, J_{F}\left(A x_{n}-B y_{n}\right)\right\rangle+k\left\|x-x_{n}\right\|^{2} .
\end{aligned}
$$

Substituting (3.3) into (3.2), we have

$$
\left\|x_{n+1}-x\right\|^{2} \leqslant \gamma^{2} L\left\|A x_{n}-B y_{n}\right\|^{2}+2 \gamma\left\langle A x-A x_{n}, J_{F}\left(A x_{n}-B y_{n}\right)\right\rangle+k\left\|x-x_{n}\right\|^{2} .
$$

Similarly we also have

$$
\left\|y_{n+1}-y\right\|^{2} \leqslant \gamma^{2} L\left\|A x_{n}-B y_{n}\right\|^{2}+2 \gamma\left\langle B y_{n}-B y_{,} J_{F}\left(A x_{n}-B y_{n}\right)\right\rangle+k\left\|y-y_{n}\right\|^{2} .
$$


Adding up (3.4) and (3.5) and noting that $A x=B y$, we have

$$
\begin{aligned}
\left\|x_{n+1}-x\right\|^{2}+\left\|y_{n+1}-y\right\|^{2} \leqslant & 2 \gamma^{2} L\left\|A x_{n}-B y_{n}\right\|^{2}-2 \gamma\left\langle\left(A x_{n}-B y_{n}\right), J_{F}\left(A x_{n}-B y_{n}\right)\right\rangle \\
& +k\left(\left\|x-x_{n}\right\|^{2}+\left\|y-y_{n}\right\|^{2}\right) .
\end{aligned}
$$

Letting $W_{n}(x, y)=\left\|x-x_{n}\right\|^{2}+\left\|y-y_{n}\right\|^{2}$, and noting $\gamma<\frac{1}{L}$ (by condition (i)) we have

$$
W_{n+1}(x, y) \leqslant k W_{n}(x, y)-2 \gamma(1-\gamma L)\left\|A x_{n}-B y_{n}\right\|^{2} \leqslant k W_{n}(x, y) \leqslant W_{n}(x, y) .
$$

This implies that the $\operatorname{limit}_{\lim _{n} \rightarrow \infty} W_{n}(x, y)$ exists. Without loss of generality we may assume that

$$
\lim _{n \rightarrow \infty} W_{n}(x, y)=W(x, y),(x, y) \in \Gamma .
$$

Hence the sequences $\left\{x_{n}\right\}$ and $\left\{y_{n}\right\}$ are bounded, so are the sequences $\left\{u_{n}\right\},\left\{v_{n}\right\},\left\{t_{n}\right\},\left\{z_{n}\right\}$.

2. Next we prove that

$$
\left\{\begin{array}{l}
\text { (1) } \lim _{n \rightarrow \infty}\left\|A x_{n}-B y_{n}\right\|=0, \\
\text { (2) } \lim _{n \rightarrow \infty}\left\|t_{n}-u_{n}\right\|=\lim _{n \rightarrow \infty}\left\|t_{n}-S_{1} t_{n}\right\|=0, \\
\text { (3) } \lim _{n \rightarrow \infty}\left\|z_{n}-v_{n}\right\|=\lim _{n \rightarrow \infty}\left\|z_{n}-S_{2} z_{n}\right\|=0, \\
\text { (4) } \lim _{n \rightarrow \infty}\left\|t_{n}-x_{n}\right\|=0, \\
\text { (5) } \lim _{n \rightarrow \infty}\left\|z_{n}-y_{n}\right\|=0 .
\end{array}\right.
$$

In fact, since $\left\{u_{n}\right\}$ and $\left\{t_{n}\right\}$ are bounded, it follows from Lemma 2.6 and (3.3) that

$$
\begin{aligned}
\left\|x_{n+1}-x\right\|^{2}= & \left\|\left(1-\beta_{n}\right)\left(u_{n}-x\right)+\beta_{n}\left(t_{n}-x\right)\right\|^{2} \\
\leqslant & \left(1-\beta_{n}\right)\left\|u_{n}-x\right\|^{2}+\beta_{n}\left\|t_{n}-x\right\|^{2}-\beta_{n}\left(1-\beta_{n}\right) g\left(\left\|u_{n}-t_{n}\right\|\right) \\
= & \left(1-\beta_{n}\right)\left\|S_{1} t_{n}-S_{1} x\right\|^{2}+\beta_{n}\left\|t_{n}-x\right\|^{2}-\beta_{n}\left(1-\beta_{n}\right) g\left(\left\|u_{n}-t_{n}\right\|\right) \\
\leqslant & \left(1-\beta_{n}\right)\left\|t_{n}-x\right\|^{2}+\beta_{n}\left\|t_{n}-x\right\|^{2}-\beta_{n}\left(1-\beta_{n}\right) g\left(\left\|u_{n}-t_{n}\right\|\right) \\
= & \left\|t_{n}-x\right\|^{2}-\beta_{n}\left(1-\beta_{n}\right) g\left(\left\|u_{n}-t_{n}\right\|\right) \\
\leqslant & \gamma^{2} L\left\|A x_{n}-B y_{n}\right\|^{2}+2 \gamma\left\langle A x-A x_{n}, J_{F}\left(A x_{n}-B y_{n}\right)\right\rangle+k\left\|x-x_{n}\right\|^{2} \\
& -\beta_{n}\left(1-\beta_{n}\right) g\left(\left\|t_{n}-u_{n}\right\|\right)
\end{aligned}
$$

Similarly we also have

$$
\begin{aligned}
\left\|y_{n+1}-y\right\|^{2} \leqslant & \gamma^{2} L\left\|A x_{n}-B y_{n}\right\|^{2}+2 \gamma\left\langle B y_{n}-B y_{,} J_{F}\left(A x_{n}-B y_{n}\right)\right\rangle+k\left\|y-y_{n}\right\|^{2} \\
& -\beta_{n}\left(1-\beta_{n}\right) g\left(\left\|z_{n}-v_{n}\right\|\right) .
\end{aligned}
$$

Adding up (3.7) and (3.8) and noting that $A x=B y$, we have

$$
\begin{aligned}
W_{n+1}(x, y) \leqslant & k W_{n}(x, y)-2 \gamma(1-\gamma L)\left\|A x_{n}-B y_{n}\right\|^{2} \\
& -\beta_{n}\left(1-\beta_{n}\right)\left(g\left(\left\|t_{n}-u_{n}\right\|\right)+g\left(\left\|z_{n}-v_{n}\right\|\right)\right),
\end{aligned}
$$

where $W_{n}(x, y)=\left\|x-x_{n}\right\|^{2}+\left\|y-y_{n}\right\|^{2}$. Simplifying and noting that the limit $\lim _{n \rightarrow \infty} W_{n}(x, y)$ exists, we have

$$
\begin{aligned}
& 2 \gamma(1-\gamma L)\left\|A x_{n}-B y_{n}\right\|^{2}+\beta_{n}\left(1-\beta_{n}\right)\left(g\left(\left\|t_{n}-u_{n}\right\|\right)+g\left(\left\|z_{n}-v_{n}\right\|\right)\right) \\
& \leqslant k W_{n}(x, y)-W_{n+1}(x, y) \leqslant W_{n}(x, y)-W_{n+1}(x, y) \rightarrow 0(\text { as } n \rightarrow \infty) .
\end{aligned}
$$

By the conditions (i), (iii), and the property of $g$ it follows that

$$
\lim _{n \rightarrow \infty}\left\|A x_{n}-B y_{n}\right\|=0
$$




$$
\begin{aligned}
& \lim _{n \rightarrow \infty}\left\|t_{n}-u_{n}\right\|=\lim _{n \rightarrow \infty}\left\|t_{n}-S_{1} t_{n}\right\|=0, \\
& \lim _{n \rightarrow \infty}\left\|z_{n}-v_{n}\right\|=\lim _{n \rightarrow \infty}\left\|z_{n}-S_{2} z_{n}\right\|=0 .
\end{aligned}
$$

These imply that

$$
\left\|t_{n}-x_{n}\right\|=\left\|J_{E_{1}}\left(t_{n}-x_{n}\right)\right\|=\left\|\gamma A^{*} J_{F}\left(A x_{n}-B y_{n}\right)\right\| \leqslant \gamma\|A\|\left\|A x_{n}-B y_{n}\right\| \rightarrow 0 \quad(\text { as } n \rightarrow \infty)
$$

and

$$
\left\|z_{n}-y_{n}\right\|=\left\|J_{E_{2}}\left(z_{n}-y_{n}\right)\right\|=\left\|\gamma B^{*} J_{F}\left(A x_{n}-B y_{n}\right)\right\| \leqslant \gamma\|B\|\left\|A x_{n}-B y_{n}\right\| \rightarrow 0 \quad(\text { as } n \rightarrow \infty) .
$$

The conclusions in (3.6) are proved.

3. Now we prove that sequence $\left\{\left(x_{n}, y_{n}\right)\right\}$ converges strongly to some point $\left(x^{*}, y^{*}\right) \in \Gamma$. Since $E_{1}$ and $E_{2}$ are uniformly convex, they are reflexive. Again since $\left\{x_{n}\right\}$ and $\left\{y_{n}\right\}$ are bounded, we may assume that $\left(x^{*}, y^{*}\right)$ is a weak cluster point of $\left\{\left(x_{n}, y_{n}\right)\right\}$. It follows from (3.9) and (3.10) that $\left(x^{*}, y^{*}\right)$ is also a weak cluster point of $\left\{\left(t_{n}, z_{n}\right)\right\}$. Again by (3.6), $\left\|t_{n}-S_{1} t_{n}\right\| \rightarrow 0$ and $\left\|z_{n}-S_{2} z_{n}\right\| \rightarrow 0$. Due to the demi-closed property at zero of $S_{1}$ and $S_{2}$ (since $S_{1}, S_{2}$ both are nonexpansive), $x^{*} \in \operatorname{Fix}\left(S_{1}\right)$ and $y^{*} \in \operatorname{Fix}\left(S_{2}\right)$. Also since $A$ and $B$ are bounded linear operators, we know that $\left(A x^{*}, B y^{*}\right)$ is also a weak cluster point of $\left\{\left(A x_{n}, B y_{n}\right)\right\}$. By the weakly lower semicontinuous property of the norm and (3.6), we get

$$
\left\|A x^{*}-B y^{*}\right\| \leqslant \liminf _{n \rightarrow \infty}\left\|A x_{n}-B y_{n}\right\|=0,
$$

i.e., $A x^{*}=B y^{*}$. Therefore $\left(x^{*}, y^{*}\right) \in \Gamma$. This implies that the weak cluster point $\left(x^{*}, y^{*}\right)$ of $\left\{\left(x_{n}, y_{n}\right)\right\}$ is a solution of split equality quasi inclusion problems (2.7).

Next we prove that $\left(x^{*}, y^{*}\right)$ is the unique weak cluster point of $\left\{\left(x_{n}, y_{n}\right)\right\}$.

Suppose to the contrary, let $(p, q)$ be another weak cluster point of $\left\{\left(x_{n}, y_{n}\right)\right\}$ with $(p, q) \neq\left(x^{*}, y^{*}\right)$. By the arguments above, we can also prove that $(p, q) \in \Gamma$.

Since $\left(x^{*}, y^{*}\right)$ and $(p, q)$ both are weak cluster points of $\left\{\left(x_{n}, y_{n}\right)\right\}$, there exist subsequences $\left\{\left(x_{n_{i}}, y_{n_{i}}\right)\right\}$ and $\left\{\left(x_{n_{j}}, y_{n_{j}}\right)\right\}$ of $\left\{\left(x_{n}, y_{n}\right)\right\}$ such that

$$
\left(x_{n_{i}}, y_{n_{i}}\right) \rightarrow\left(x^{*}, y^{*}\right) \quad\left(\text { as } n_{i} \rightarrow \infty\right) \text { and }\left(x_{n_{j}}, y_{n_{j}}\right) \rightarrow(p, q) \quad\left(\text { as } n_{j} \rightarrow \infty\right) .
$$

By Lemma 2.5 (2), we have

$$
\begin{aligned}
W_{n_{i}}\left(x^{*}, y^{*}\right)= & \left\|x_{n_{i}}-x^{*}\right\|^{2}+\left\|y_{n_{i}}-y^{*}\right\|^{2} \\
= & \left\|x_{n_{i}}-p+p-x^{*}\right\|^{2}+\left\|y_{n_{i}}-q+q-y^{*}\right\|^{2} \\
\leqslant & \left\|p-x^{*}\right\|^{2}+2\left\langle x_{n_{i}}-p, J_{E_{1}}\left(p-x^{*}\right)\right\rangle+k\left\|x_{n_{i}}-p\right\|^{2} \\
& +\left\|q-y^{*}\right\|^{2}+2\left\langle y_{n_{i}}-q, J_{E_{2}}\left(q-y^{*}\right)\right\rangle+k\left\|y_{n_{i}}-q\right\|^{2} .
\end{aligned}
$$

Simplifying it we have

$$
\begin{aligned}
W_{n_{i}}\left(x^{*}, y^{*}\right)-k W_{n_{i}}(p, q) \leqslant & \left\|p-x^{*}\right\|^{2}+\left\|q-y^{*}\right\|^{2} \\
& +2\left\langle x_{n_{i}}-p, J_{E_{1}}\left(p-x^{*}\right)\right\rangle+2\left\langle y_{n_{i}}-q, J_{E_{2}}\left(q-y^{*}\right)\right\rangle .
\end{aligned}
$$

Letting $n_{i} \rightarrow \infty$ in (3.11) and noting (3.6), we have

$$
\begin{aligned}
W\left(x^{*}, y^{*}\right)-k W(p, q) & \leqslant\left\|p-x^{*}\right\|^{2}+\left\|q-y^{*}\right\|^{2}+2\left\langle x^{*}-p, J_{E_{1}}\left(p-x^{*}\right)\right\rangle+2\left\langle y^{*}-q, J_{E_{2}}\left(q-y^{*}\right)\right\rangle . \\
& =\left\|p-x^{*}\right\|^{2}+\left\|q-y^{*}\right\|^{2}-2\left(\left\|p-x^{*}\right\|^{2}+\left\|q-y^{*}\right\|^{2}\right) \\
& =-\left(\left\|p-x^{*}\right\|^{2}+\left\|q-y^{*}\right\|^{2}\right)
\end{aligned}
$$

Similarly we can also obtain the following inequality

$$
\begin{aligned}
W_{n_{j}}(p, q)-k W_{n_{j}}\left(x^{*}, y^{*}\right) \leqslant & \left\|p-x^{*}\right\|^{2}+\left\|q-y^{*}\right\|^{2} \\
& +2\left\langle x_{n_{j}}-x^{*}, J_{E_{1}}\left(x^{*}-p\right)+2\left\langle y_{n_{j}}-y^{*}, J_{E_{2}}\left(y^{*}-q\right)\right\rangle .\right.
\end{aligned}
$$


Letting $n_{j} \rightarrow \infty$ in (3.13) we have

$$
W(p, q)-k W\left(x^{*}, y^{*}\right) \leqslant-\left(\left\|p-x^{*}\right\|^{2}+\left\|q-y^{*}\right\|^{2}\right) .
$$

Adding up (3.12) and (3.14), we have

$$
0 \leqslant(1-k)\left(W(p, q)+W\left(x^{*}, y^{*}\right)\right) \leqslant-2\left(\left\|p-x^{*}\right\|^{2}+\left\|q-y^{*}\right\|^{2}\right) \leqslant 0 .
$$

This implies that

$$
\left(\left\|p-x^{*}\right\|^{2}+\left\|q-y^{*}\right\|^{2}\right)=0 \text { and } W(p, q)=W\left(x^{*}, y^{*}\right)=0
$$

Hence we have

$$
p=x^{*}, q=y^{*} \text { and } W(p, q)=W\left(x^{*}, y^{*}\right)=0 .
$$

These show that $\left(x^{*}, y^{*}\right)$ is the unique weak cluster point of $\left\{\left(x_{n}, y_{n}\right)\right\}$, i.e., $\left(x_{n}, y_{n}\right) \rightarrow\left(x^{*}, y^{*}\right)$ and $\lim _{n_{i} \rightarrow \infty} W_{n_{i}}\left(x^{*}, y^{*}\right)=W\left(x^{*}, y^{*}\right)=0$. Since the $\operatorname{limit}_{\lim _{n \rightarrow \infty}} W_{n}\left(x^{*}, y^{*}\right)$ exists, we have

$$
\lim _{n \rightarrow \infty} W_{n}\left(x^{*}, y^{*}\right)=\lim _{n \rightarrow \infty}\left(\left\|x_{n}-x^{*}\right\|^{2}+\left\|y_{n}-y^{*}\right\|^{2}\right)=0,
$$

i.e., $\lim _{n \rightarrow \infty} x_{n}=x^{*}$ and $\lim _{n \rightarrow \infty} y_{n}=y^{*}$. This completes the proof of Theorem 3.1.

The following theorems can be obtained from Theorem 3.1 immediately.

Theorem 3.2. Let $\mathrm{E}_{1}, \mathrm{E}_{2}$ be real uniformly convex and 2-uniformly smooth Banach spaces with the best smoothness constant $k \in] 0,1]$. Let $\mathrm{G}_{i}: \mathrm{E}_{i} \rightarrow \mathrm{E}_{i}, i=1,2$ be $\alpha$-isa of order 2 and $\mathrm{K}_{i}: \mathrm{E}_{i} \rightrightarrows \mathrm{E}_{i}, i=1,2$ be set-valued m-accretive mappings, and $\mathrm{A}: \mathrm{E}_{1} \rightarrow \mathrm{E}_{2}$ be a linear bounded operator. For any $\left(\mathrm{x}_{0}, \mathrm{y}_{0}\right) \in \mathrm{E}_{1} \times \mathrm{E}_{2}$, the sequence $\left\{\left(x_{n}, y_{n}\right)\right\}$ is generated by

$$
\left\{\begin{array}{l}
u_{n}=J_{r}^{K_{1}}\left(I-r G_{1}\right)\left(x_{n}-\gamma J_{E_{1}}^{-1} A^{*} J_{E_{2}}\left(A x_{n}-y_{n}\right)\right), \\
v_{n}=J_{r}^{K_{2}}\left(I-r G_{2}\right)\left(y_{n}+\gamma\left(A x_{n}-y_{n}\right)\right), \\
x_{n+1}=\left(1-\beta_{n}\right) u_{n}+\beta_{n}\left(x_{n}-\gamma J_{E_{1}}^{-1} A^{*} J_{E_{2}}\left(A x_{n}-y_{n}\right)\right), \\
y_{n+1}=\left(1-\beta_{n}\right) v_{n}+\beta_{n}\left(y_{n}+\gamma\left(A x_{n}-y_{n}\right)\right),
\end{array} \quad \forall n \geqslant 1,\right.
$$

where $\mathrm{J}_{r}^{\mathrm{K}_{i}}:=\left(\mathrm{I}+\mathrm{rK}_{i}\right)^{-1}, i=1,2$ are the resolvent operators of mappings $\mathrm{K}_{i}, \mathrm{~J}_{\mathrm{E}_{i}}, i=1,2$ are the normalized duality mappings of $\mathrm{E}_{i}, i=1,2$, and $\mathrm{A}^{*}$ is the adjoint of $\mathrm{A}$. If

$$
\Gamma:=\left\{(x, y) \in \operatorname{Fix}\left(J_{r}^{K_{1}}\left(I-r G_{1}\right)\right) \times \operatorname{Fix}\left(J_{r}^{K_{2}}\left(I-r G_{2}\right)\right), A x=y\right\} \neq \emptyset
$$

and the following conditions are satisfied:

(i) $0<\gamma<\frac{1}{\mathrm{~L}}$, where $\mathrm{L}=\max \left\{\left\|A^{*} A\right\|, 1\right\}$;

(ii) $0<\mathrm{r} \leqslant \frac{2 \alpha}{k}$;

(iii) $\left\{\beta_{n}\right\}$ is the sequence in $] 0,1\left[\right.$ with $\lim \inf \beta_{n}\left(1-\beta_{n}\right)>0$,

then the sequence $\left\{\left(x_{n}, y_{n}\right)\right\}$ converges strongly to a solution $\left(x^{*}, A x^{*}\right)$ of split equality quasi inclusion problem (2.2).

Theorem 3.3. Let $\mathrm{E}$ be a real uniformly convex and 2-uniformly smooth Banach spaces with the best smoothness constant $\mathrm{k} \in] 0,1]$. Let $\mathrm{G}: \mathrm{E} \rightarrow \mathrm{E}$ be $\alpha$-isa of order 2 and $\mathrm{K}: \mathrm{E} \rightrightarrows \mathrm{E}$ be m-accretive mappings. For any $\mathrm{x}_{0} \in \mathrm{E}$, the sequence $\left\{x_{n}\right\}$ is generated by

$$
\left\{\begin{array}{l}
u_{n}=J_{r}^{K}(I-r G)\left(x_{n}\right), \\
x_{n+1}=\left(1-\beta_{n}\right) u_{n}+\beta_{n} x_{n},
\end{array} \quad \forall n \geqslant 1,\right.
$$

where $\mathrm{J}_{\mathrm{r}}^{\mathrm{K}}:=(\mathrm{I}+\mathrm{rK})^{-1}$ is the resolvent operator of mapping $\mathrm{K}$. If

$$
\Gamma:=\left\{x \in \operatorname{Fix}\left(\mathrm{J}_{\mathrm{r}}^{\mathrm{K}}(\mathrm{I}-\mathrm{rG})\right)\right\} \neq \emptyset
$$

and the following conditions are satisfied: 
(i) $0<\mathrm{r} \leqslant \frac{2 \alpha}{\mathrm{k}}$;

(ii) $\left\{\beta_{n}\right\}$ is the sequence in $] 0,1\left[\right.$ with $\lim \inf \beta_{n}\left(1-\beta_{n}\right)>0$,

then the sequence $\left\{x_{n}\right\}$ converges strongly to a solution $x^{*}$ of quasi inclusion problem (2.3).

Remark 3.4. Theorems 3.1 and 3.2 are improvements and generalizations of $[3,4,9-11,15,20]$.

\section{Applications}

In this section we shall utilize the results presented in the paper to study the monotone variational inequality problem, convex minimization problem, and convexly constrained linear inverse problem.

Throughout this section, let $\mathrm{C}$ be a nonempty closed and convex subset of a real Hilbert space $\mathrm{H}$. Note that in this case the concept of monotonicity coincides with the concept of accretivity.

\subsection{Application to monotone variational inequality problems}

A monotone variational inequality problem (VIP) is formulated as the problem of finding a point $x^{*} \in \mathrm{C}$ such that:

$$
\left\langle G x^{*}, y-x^{*}\right\rangle \geqslant 0, \quad \forall y \in C,
$$

where $\mathrm{G}: \mathrm{C} \rightarrow \mathrm{H}$ is a nonlinear monotone operator. We shall denote by $\Gamma$ the solution set of (4.1) and assume $\Gamma \neq \emptyset$. In Example 2.4, we have pointed out that VIP (4.1) is equivalent to find a point $x^{*}$ so that

$$
0 \in(\mathrm{G}+\mathrm{K}) \mathrm{x}^{*},
$$

where $\mathrm{K}: \mathrm{C} \rightarrow \mathrm{H}$ is the subdifferential of the indicator of $\mathrm{C}$, and it is a maximal monotone operator. By [16, Theorem 3] in this case, the resolvent of $K$ is nothing but the projection operator $P_{C}$. Therefore the following result can be obtained from Theorem 3.3 immediately.

Theorem 4.1. Let $\mathrm{G}: \mathrm{C} \rightarrow \mathrm{H}$ be an $\alpha$-inverse strongly monotone operator of order 2 . Let $\left\{x_{n}\right\}$ be the sequence generated by $\mathrm{x}_{0} \in \mathrm{C}$ and

$$
\left\{\begin{array}{l}
u_{n}=P_{C}(I-r G)\left(x_{n}\right), \\
x_{n+1}=\left(1-\beta_{n}\right) u_{n}+\beta_{n} x_{n},
\end{array} \quad \forall n \geqslant 1 .\right.
$$

If

$$
\Gamma:=\left\{x \in \operatorname{Fix}\left(\mathrm{P}_{\mathrm{C}}(\mathrm{I}-\mathrm{rG})\right)\right\} \neq \emptyset
$$

and the following conditions are satisfied:

(i) $0<r \leqslant 2 \alpha$;

(ii) $\left\{\beta_{n}\right\}$ is the sequence in $] 0,1\left[\right.$ with $\lim \inf \beta_{n}\left(1-\beta_{n}\right)>0$,

then the sequence $\left\{x_{n}\right\}$ converges strongly to a solution $x^{*}$ of monotone variational inequality (4.1).

\subsection{Application to the convex minimization problem}

Let $\psi: \mathrm{H} \rightarrow \mathrm{R}$ be a convex smooth function and $\phi: \mathrm{H} \rightarrow \mathrm{R}$ be a proper convex and lower semicontinuous function. We consider the following convex minimization problem of finding $x^{*} \in \mathrm{H}$ such that

$$
\psi\left(x^{*}\right)+\phi\left(x^{*}\right)=\min _{x \in H}\{\psi(x)+\phi(x)\} .
$$

This problem (4.2) is equivalent, by Fermat's rule, to the problem of finding $x^{*} \in \mathrm{H}$ such that

$$
0 \in \nabla \psi\left(x^{*}\right)+\partial \phi\left(x^{*}\right),
$$

where $\nabla \psi$ is a gradient of $\psi$ and $\partial \phi$ is a subdifferential of $\phi$. Set $G=\nabla \psi$ and $K=\partial \phi$ in Theorem 3.3. If $\nabla \psi$ is $(1 / \mathrm{L})$-Lipschitz continuous, then it is L-inverse strongly monotone. Moreover, $\partial \phi$ is maximal monotone. Hence from Theorem 3.3 we have the following result. 
Theorem 4.2. Let $\psi: \mathrm{H} \rightarrow \mathrm{R}$ be a convex and differentiable function with (1/L)-Lipschitz continuous gradient $\nabla \psi$ and $\phi: \mathrm{H} \rightarrow \mathrm{R}$ be a proper convex and lower semicontinuous function such that $\psi+\phi$ attains a minimizer. Let $\left\{x_{n}\right\}$ be the sequence generated by $x_{0} \in \mathrm{H}$ and

$$
\left\{\begin{array}{l}
u_{n}=J_{r}^{K}(I-r G)\left(x_{n}\right), \\
x_{n+1}=\left(1-\beta_{n}\right) u_{n}+\beta_{n} x_{n},
\end{array} \quad \forall n \geqslant 1,\right.
$$

where $\mathrm{G}=\nabla \psi, \mathrm{K}=\partial \phi$, and $\mathrm{J}_{\mathrm{r}}^{\mathrm{K}}:=(\mathrm{I}+\mathrm{rK})^{-1}$. If the following conditions are satisfied:

(i) $0<r \leqslant 2 \alpha$;

(ii) $\left\{\beta_{n}\right\}$ is the sequence in $] 0,1\left[\right.$ with $\lim \inf \beta_{n}\left(1-\beta_{n}\right)>0$,

then the sequence $\left\{x_{n}\right\}$ converges strongly to a solution $x^{*}$ of convex minimization problem (4.2).

4.3. Application to the convexly constrained linear inverse problem

Let $A: H \rightarrow C$ be a bounded linear operator and $b \in C$. The constrained linear system

$$
A x=b, x \in C
$$

is called convexly constrained linear inverse problem. Define $\psi(x): H \rightarrow \mathrm{R}^{+}$by

$$
\psi(x)=\frac{1}{2}\|A x-b\|^{2}, x \in H .
$$

We have $\nabla \psi(x)=A^{*}(A x-b)$, and $\nabla \psi$ is L-Lipschitzian, where $L=\|A\|^{2}$, i.e., $\nabla \psi$ is $1 /$ L-inverse strongly monotone. It is easy to know that $x^{*} \in C$ is a solution of (4.3) if and only if $0 \in \nabla \psi\left(x^{*}\right)=A^{*}\left(A x^{*}-b\right)$. Taking $\mathrm{G}=\nabla \psi$ and $\mathrm{K}=0$ in Theorem 3.3 we have the following result.

Theorem 4.3. If problem (4.3) is consistent and the following conditions are satisfied:

(i) $0<\mathrm{r} \leqslant 2 \alpha$;

(ii) $\left\{\beta_{n}\right\}$ is the sequence in $] 0,1\left[\right.$ with $\lim \inf \beta_{n}\left(1-\beta_{n}\right)>0$,

then the sequence $\left\{x_{n}\right\}$ generated by $x_{0} \in \mathrm{H}$ and

$$
\left\{\begin{array}{l}
u_{n}=P_{C}(I-r G)\left(x_{n}\right), \\
x_{n+1}=\left(1-\beta_{n}\right) u_{n}+\beta_{n} x_{n},
\end{array} \quad \forall n \geqslant 1,\right.
$$

converges strongly to a solution $x^{*}$ of problem (4.3).

\section{Conclusions}

The quasi inclusion problem for monotone and the maximal monotone mappings in Hilbert spaces has been considered by many authors. How to generalize and extend this problem from Hilbert space to Banach space is difficult. The purpose of this paper is to try to solve such a problem.

In our paper, we introduce and study the general split equality quasi inclusion problems of accretive and m-accretive operators in Banach spaces which contain split quasi inclusion problem and the quasi inclusion problem in Banach spaces as its special cases. For solving this problem, a new generalized forward-backward algorithms are proposed. Under suitable conditions, some strong convergence theorems for the sequences generated by the algorithm to a solution of the problem are proved (see Theorems 3.1, 3.2, and 3.3). At the end of the paper, some applications to monotone variational inequality problem, convex minimization problem, and convexly constrained linear inverse problem are presented. The results presented in the paper are new. 


\section{Acknowledgment}

The work is supported by the Natural Sci. Found. of Center for General Education, China Medical University, Taichung, Taiwan and the Research Center for Nonlinear Analysis and Optimization, Kaohsiung Medical University, Taiwan. C. F. Wen was partially supported by the Grant MOST 106-2115M-037-001. J. C. Yao was partially supported by the Grant MOST 106-2923-E-039-001-MY3.

\section{References}

[1] C. Byrne, A unified treatment of some iterative algorithms in signal processing and image reconstruction, Inverse Problems, 20 (2004), 103-120. 1, 2, 2

[2] S.-S. Chang, L. Wang, L.-J. Qin, Z.-L. Ma, Strongly convergent iterative methods for split equality variational inclusion problems in Banach spaces, Acta Math. Sci. Ser. B Engl. Ed., 36 (2016), 1641-1650. 1, 2

[3] G. H.-G. Chen, R. T. Rockafellar, Convergence rates in forward-backward splitting, SIAM J. Optim., 7 (1997), $421-444$. $1,2,1,3.4$

[4] P. Cholamjiak, A generalized forward-backward splitting method for solving quasi inclusion problems in Banach spaces, Numer Algor, 71 (2016), 915-932. 1, 2, 3.4

[5] I. Cioranescu, Geometry of Banach Spaces, Duality Mappings and Nonlinear Problems, Kluwer Academic Publishers, Dordrecht, (1990). 2, 2.7

[6] P. L. Combettes, Iterative construction of the resolvent of a sum of maximal monotone operators, J. Convex Anal., 16 (2009), 727-748. 1, 2

[7] P. L. Combettes, V. R. Wajs, Signal recovery by proximal forward-backward splitting, Multiscale Model. Simul., 4 (2005), 1168-1200. 1, 2, 2

[8] O. Güler, On the convergence of the proximal point algorithm for convex minimization, SIAM J. Control Optim., 29 (1991), 403-419. 1, 2

[9] S. Kamimura, W. Takahashi, Approximating solutions of maximal monotone operators in Hilbert spaces, J. Approx. Theory, 106 (2000), 226-240. 3.4

[10] P.-L. Lions, B. Mercier, Splitting algorithms for the sum of two nonlinear operators, SIAM J. Numer. Anal., 16 (1979), 964-979. 1, 2

[11] G. López, V. Martín-Márquez, F. Wang, H. K. Xu, Forward-Backward splitting methods for accretive operators in Banach spaces, Abstr. Appl. Anal., 2012 (2012), 25 pages. 1, 2, 2.9, 3.4

[12] G. Marino, H.-K. Xu, Convergence of generalized proximal point algorithm, Comm. Pure Appl. Anal., 3 (2004), 791-808. 1,2

[13] A. Moudafi, Split monotone variational inclusions, J. Optim. Theory Appl., 150 (2011), 275-283. 2

[14] A. Moudafi, A relaxed alternating CQ algorithm for convex feasibility problems, Nonlinear Anal, 79 (2013), $117-121$.

[15] A. Moudafi, E. Al-Shemas, Simultaneouss iterative methods for split equality problem, Trans. Math. Program Appl, 1 (2013), 1-11. 1, 2, 3.4

[16] R. T. Rockafellar, On the maximality of sums of nonlinear monotone operators, Trans. Amer. Math. Soc., 149 (1970), 75-88. 4.1

[17] R. T. Rockafellar, Monotone operators and the proximal point algorithm, SIAM J. Control Optimization, 14 (1976), 877-898. 1, 2, 2

[18] S. Sra, S. Nowozin, S. J. Wright, Optimization for Machine Learning, MIT Press, England, (2011). 2

[19] W. Takahashi, Iterative methods for split feasibility problems and split common null point problems in Banach spaces, The 9th International Conference on Nonlinear Analysis and Convex Analysis. Thailand, Jan: Chiang Rai, (2015), 21-25. 1

[20] W. Takahashi, N.-C. Wong, J.-C. Yao, Two generalized strong convergence theorems of Halpern's type in Hilbert spaces and applications, Taiwanese J. Math., 16 (2012), 1151-1172. 1, 3.4

[21] P. Tseng, A modified forward-backward splitting method for maximal monotone mappings, SIAM J. Control Optim., 38 (2000), 431-446. 1

[22] H. K. Xu, Inequalities in Banach spaces with applications, Nonlinear Anal., 16 (1991), 1127-1138. 2, 2.6 